\title{
Minimally invasive mitral valve repair suggests earlier operations for mitral valve disease
}

\author{
James P. Greelish, MD \\ Lawrence H. Cohn, MD \\ Marzia Leacche, MD \\ Michael Mitchell, MD \\ Alexandros Karavas, MD \\ John Fox, MD \\ John G. Byrne, MD \\ Sary F. Aranki, MD \\ Gregory S. Couper, MD
}

From the Brigham and Women's Hospital, Boston, Mass.

Read at the Twenty-seventh Annual Meeting of The Western Thoracic Surgical Association, Big Sky, Mont, June 19-22, 2002.

Received for publication July 12, 2002; accepted for publication Oct 16, 2002.

Address for reprints: Lawrence H. Cohn, MD, Brigham and Women's Hospital, 75 Francis Street, Boston, MA 02115 (E-mail: lcohn@partners.org).

J Thorac Cardiovasc Surg 2003;126:365-73

Copyright $(2) 2003$ by The American Association for Thoracic Surgery

$0022-5223 / 2003 \$ 30.00+0$

doi:10.1016/S0022-5223(03)00078-3
Objective: We began minimally invasive mitral valve surgery in August, 1996, to reduce hospital costs, to improve patient recovery, cosmetic appearance, and to decrease trauma, yet maintain the same quality of surgery. To validate this approach we reviewed our entire experience through May 2002.

Methods: From August 1996 to May 2002, we performed 413 minimally invasive mitral valve operations including 51 mitral valve replacements and 362 mitral valve repairs. Excluding 4 robotically assisted repairs, we evaluated 358 patients, using the mitral valve repairs as the basis for this retrospective survey. These operations were performed through a 6- to 8-cm minimally invasive incision, beginning with parasternal and, most recently, lower ministernotomy (181 patients). The mitral valve reparative techniques include repair of 94 prolapsed anterior leaflets, posterior leaflet resection, leaflet advancement, commissuroplasty, Polytetrafluoroethylene (PTFE; Gore-Tex, W. L. Gore \& Associates, Inc, Flagstaff, Ariz) chordal placement, and ring annuloplasty. Cannulation sites varied but primarily utilized a miniaturized system of $24 \mathrm{~F}$ catheters in both the inferior and superior venae cavae with assisted venous suction. The Cosgrove ring was used in $95 \%$ of the patients undergoing this procedure.

Results: The operative mortality was $0 / 358$. Perioperative morbidity included a $26 \%$ incidence of new atrial fibrillation, $2 \%$ incidence of pacemaker implantation, $0.5 \%$ incidence of deep sternal wound infection, and $1.9 \%$ incidence of stroke after an operation. There were 10 arterial and 3 venous complications. The mean length of stay was 6 days and 208 patients stayed $\leq 5$ days. Only $25 \%$ of the patients underwent homologous blood transfusion. The mean follow-up was 36 months with $1.4 \%$ lost to follow-up. There were 12 late deaths and a survival at 5 years of $95 \%$. There were 21 valves requiring reoperation for structural valve failure of $5.8 \%$. The probability of freedom from reoperation at 5 years was $92 \%$.

Conclusion: This study documents the safety of minimally invasive mitral valve repair surgery in 358 patients. It also documents a low incidence of homologous blood use, requirement for post-hospital rehabilitation, and general morbidity.

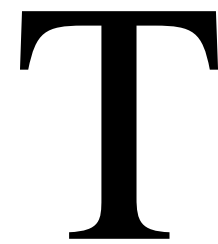

o decrease trauma, reduce cost, and speed patient recovery, yet maintain the same quality of surgery, we began minimally invasive mitral valve surgery in $1996 .{ }^{1}$ This approach has been performed in patients who have isolated mitral valve disease without concomitant coronary artery disease. We retrospectively reviewed our entire consecutive experience of minimally invasive mitral valve repairs to determine the long-term survival and reoperation for valve failure. 
TABLE 1. Preoperative patient demographics $(N=358)$

\begin{tabular}{|c|c|c|}
\hline \multicolumn{3}{|l|}{ Age (y) } \\
\hline Range & $17-89$ & \\
\hline Mean & $57 \pm 13$ & \\
\hline \multicolumn{3}{|l|}{ Gender } \\
\hline Male & 216 & $60 \%$ \\
\hline Female & 142 & $40 \%$ \\
\hline Mean NYHA functional class & $2.2 \pm 0.6$ & \\
\hline Mean ejection fraction (\%) & $59 \pm 11$ & \\
\hline $\begin{array}{l}\text { Pulmonary hypertension (PAP > } \\
30 \mathrm{~mm} \mathrm{Hg} \text { ) }\end{array}$ & 124 & $35 \%$ \\
\hline \multicolumn{3}{|l|}{ Mitral valve pathophysiology } \\
\hline Mitral regurgitation & 350 & $98 \%$ \\
\hline Mitral stenosis & 0 & \\
\hline Mixed & 8 & $2 \%$ \\
\hline \multicolumn{3}{|l|}{ Mitral valve disease ${ }^{*}$} \\
\hline Myxomatous & 325 & $91 \%$ \\
\hline Anterior leaflet prolapse & 23 & $6 \%$ \\
\hline Bileaflet prolapse & 71 & $20 \%$ \\
\hline Posterior leaflet prolapse & 231 & \\
\hline Rheumatic & 14 & $4 \%$ \\
\hline Endocarditis & 23 & $6 \%$ \\
\hline Ischemic & 1 & $0.2 \%$ \\
\hline Congenital & 2 & $0.5 \%$ \\
\hline Dilatative cardiomyopathy & 7 & $2 \%$ \\
\hline Calcific/degenerative & 3 & $1 \%$ \\
\hline Other & 3 & $1 \%$ \\
\hline Preoperative atrial fibrillation & 102 & $28 \%$ \\
\hline \multicolumn{3}{|l|}{ Coronary artery disease } \\
\hline None & 353 & $98.6 \%$ \\
\hline One vessel & 5 & $1.3 \%$ \\
\hline No intervention & 2 & \\
\hline Preoperative PTCA & 2 & \\
\hline Isolated CABG & 1 & \\
\hline
\end{tabular}

NYHA, New York Heart Association functional classification; PAP, pulmonary artery pressure; PTCA, percutaneous transluminal coronary angioplasty; $C A B G$, coronary artery bypass grafting.

*Numbers indicate multiple abnormalities in a single patient.

\section{Patients and Methods \\ Patients}

From August 1, 1996, to May 1, 2002, 413 patients underwent minimally invasive mitral valve surgery. Fifty-one patients $(12 \%)$ had a mitral valve replacement and $362(88 \%)$ had mitral valve repair. During the same period, a total of 526 patients underwent isolated mitral valve repair; thus the 362 minimally invasive patients represent $69 \%$ of mitral valve repair operations at our institution during that time. Four patients had a robotically assisted repair and are excluded, leaving 358 patients for review.

Patient demographics are shown in Table 1. The mean age was 57 years, $60 \%$ were men, and the mean functional class was $2.2 \pm$ 2.6. The mean left ventricular ejection fraction was $59 \% \pm 11 \%$, and pulmonary hypertension established by right heart catheterization or echocardiography was found in 124 (35\%) of patients. Mitral valve pathophysiology was predominantly regurgitant in $350(98 \%)$ and mixed stenotic and regurgitant in 8 patients $(2 \%)$. Most patients had myxomatous degenerated, prolapsed valves, which accounted for approximately $90 \%$ of the valve diseases, although a small group had a variety of other conditions including rheumatic disease, endocarditis, ischemia, and congenital and di-
TABLE 2. Surgical technique: Incision and cardiopulmonary bypass $(\mathrm{N}=358)$

\begin{tabular}{lrc}
\hline Incision & & \\
$\quad$ Lower ministerntotomy & 181 & $50 \%$ \\
Right parasternal & 168 & $46.4 \%$ \\
$\quad$ Right thoracotomy & 9 & $2.5 \%$ \\
Surgical approach & 75 & \\
$\quad$ Left atrium & 283 & $78.3 \%$ \\
$\quad$ Right atrium & & \\
Cannulation for CPB & & \\
$\quad$ Arterial cannulation & 230 & $63.5 \%$ \\
$\quad$ Aorta & 128 & $36 \%$ \\
$\quad$ Femoral artery & 134 & $37 \%$ \\
$\quad$ Venous cannulation & 224 & $62 \%$ \\
$\quad$ Right atrium-bicaval & & \\
$\quad$ Femoral vein/SVC or IVC & 309 & $87 \%$ \\
Cardioplegia & 49 & $13 \%$ \\
$\quad$ Antegrade only & & \\
Antegrade and retrograde & $86 \pm 30$ & \\
Operative duration (min) & $128 \pm 40$ & \\
$\quad$ Mean aortic crossclamp &
\end{tabular}

$\overline{C P B}$, Cardiopulmonary bypass; $S V C$, superior vena cava; $I V C$, inferior vena cava.

lated cardiomyopathy. Preoperative chronic atrial fibrillation was found in $102(28 \%)$ of patients. Single vessel coronary disease was present in 5 patients. All patients were reviewed from January to May 2002 either by clinical examination or by telephone interview with the patient or the patient's local physician.

\section{Surgical Technique}

Table 2 lists the surgical approaches that have evolved over the 6 years of this study. Our first approach, beginning in August 1996, was a right parasternal incision, which was performed in 168 patients. This approach was abandoned approximately 3 years ago for cosmetic reasons. A right thoracotomy has been performed in 9 patients. The incision currently used is a 6- to 8-cm lower ministernotomy, which was performed in 181 patients. The technique of choice for exposure of the mitral valve was the right atrial transseptal approach performed in 283 patients $(78 \%)$ with the left atrial incision used in 79 patients. Over the past 12 months the left atrial approach has become the exposure of choice because of improved instruments to expose the valve through the left atrial incision.

Initially, some patients underwent peripheral cannulation to minimize cannulas in the chest to improve exposure, particularly in deep-chested individuals. Table 2 indicates the site of arterial cannulation for cardiopulmonary bypass, which includes $128 \mathrm{fem}$ oral artery cannulations and 230 in the ascending aorta. Percutaneous inferior vena cava (IVC) cannulation via the femoral vein was used in 224 patients. Of those, 16 patients underwent both percutaneous femoral vein and jugular vein cannulation for IVC and superior vena cava (SVC) cannulation, respectively, thus keeping both atrial cannulas out of the incision. Peripheral venous cannulation is transesophageal, using a guide wire. In addition, the use of miniaturized techniques for cardiopulmonary bypass has further improved exposure, particularly with peripheral venous 

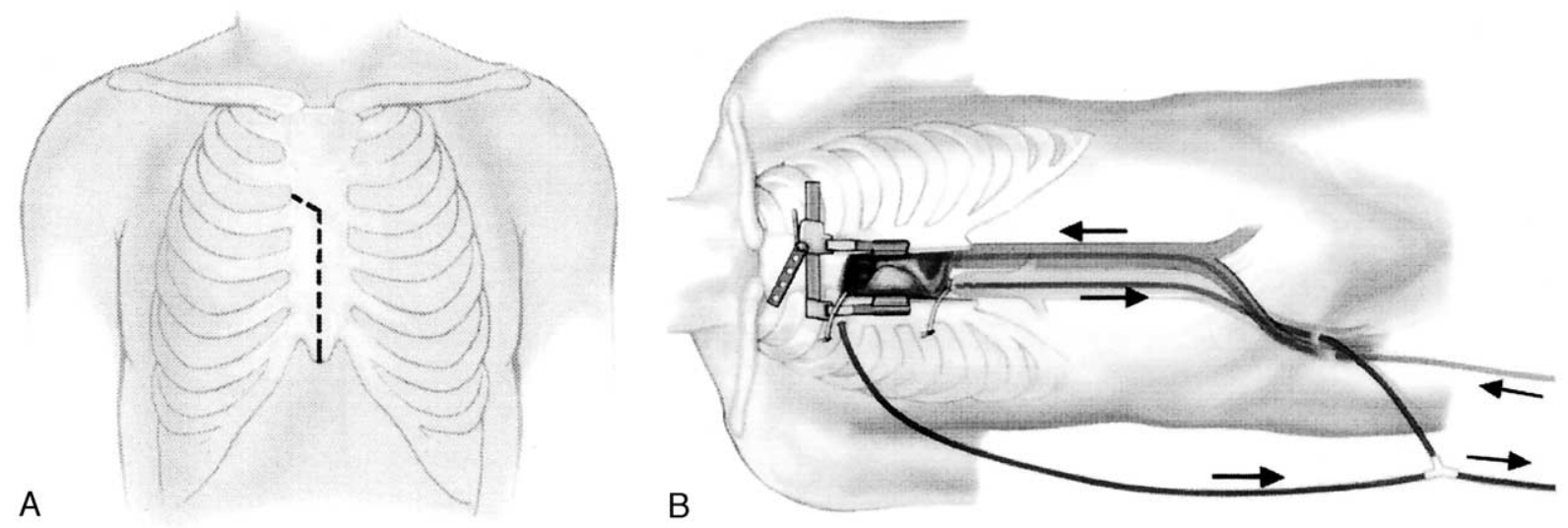

C

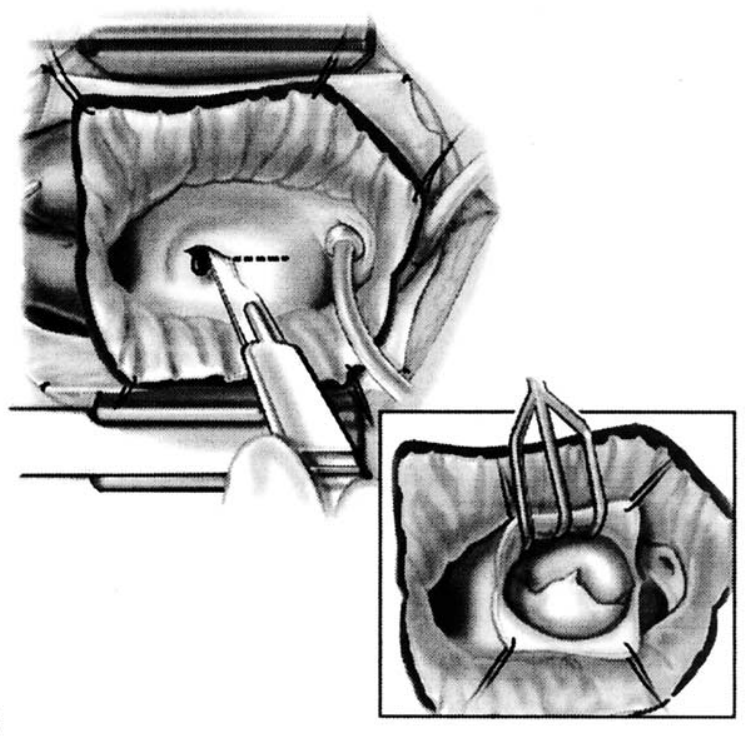

Figure 1. A, Lower ministernotomy incision. B, Cardiopulmonary bypass perfusion setup for ministernotomy approach to the mitral valve. C, Transseptal exposure of the mitral valve.

cannulation using $16 \mathrm{~F}$ to $24 \mathrm{~F}$ cannulas with the aid of assisted venous suction. ${ }^{2}$ The femoral artery has been cannulated by the Seldinger technique without incising the artery.

We have adopted our current technique of lower ministernotomy (Figure 1), based on the work by Doty and coworkers, ${ }^{3}$ who have used this incision for a variety of cardiac operations. Cardioplegia was used in all patients; 309 had antegrade and 49 patients had both antegrade and retrograde routes used. Intracardiac air was actively removed by cardiac filling and active aortic root suction. Air removal was monitored by transesophageal echocardiography in all patients.

Table 3 outlines the mitral valve reparative techniques. The majority of patients had a posterior leaflet resection and sliding valvuloplasty with placement of an annuloplasty ring. A considerable number of patients underwent reduction of prolapse of the anterior leaflet of the mitral valve, including 94 patients who had anterior leaflet resection, chordal plasty, or commissuroplasty. The most frequently inserted ring annuloplasty device was the Cos-
grove-Edwards ring (Edwards Lifesciences, Irvine, Calif) with a smaller number using a Carpentier-Edwards ring (Edwards Lifesciences). In 20 patients no ring was used because of no perceived annular dilatation, production of severe systolic anterior motion, or concern about recent acute endocarditis.

Intraoperative mitral regurgitation (MR) was estimated by transesophageal echocardiography in all patients at the time of the operation (Figure 2). Preoperatively, all patients had 3+ to $4+\mathrm{MR}$. Postoperatively, echocardiography showed the vast majority had 0 to $1+$ MR. Twenty-four patients had concomitant procedures including closure of atrial septal defects, tricuspid valve repairs, and a coronary artery bypass graft to the right coronary artery in one patient.

\section{Results}

Early and late results were tabulated by the Brigham Cardiac Valve Center database. Operative and perioperative 


\section{4+ severe \\ $3+$ moderate \\ 2+ mild \\ $1+$ trace \\ 0}

공

A
Preop Mitral Regurgitation
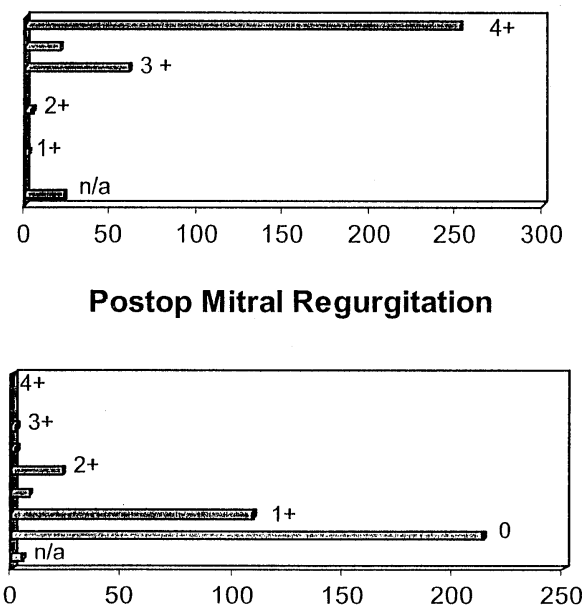

Figure 2. A, Intraoperative prerepair mitral regurgitation by TEE. B, Intraoperative post-repair mitral regurgitation by transesophageal echocardiography.

TABLE 3. Surgical technique ( $N=358$ )

\begin{tabular}{lrc}
\hline Mitral valve repair* & & \\
Posterior leaflet resection and & 295 & $82 \%$ \\
$\quad$ sliding valvuloplasty & & \\
Commissuroplasty & 62 & $17 \%$ \\
Chordoplasty & 32 & $9 \%$ \\
Anterior leaflet resection & 5 & $1 \%$ \\
Cleft closure & 13 & $3 \%$ \\
Decalcification & 11 & $3 \%$ \\
Imbrication suture & 15 & $4 \%$ \\
Compression suture & 1 & $0.3 \%$ \\
Alfieri stitch & 27 & $7 \%$ \\
Annuloplasty only & 15 & $4 \%$ \\
Valve debridement & 3 & $1 \%$ \\
Ring annuloplasty & & \\
Cosgrove ring & 321 & $90 \%$ \\
Carpentier-Edwards classic rigid & 4 & $1.2 \%$ \\
$\quad$ ring & & \\
Carpentier-Edwards Physio ring & 12 & $3 \%$ \\
None & 20 & $5.5 \%$ \\
Pericardial strip & 1 & $0.3 \%$ \\
Secondary procedures & & \\
ASD & 11 & $18 \%$ \\
TVP & 8 & $2 \%$ \\
TVP and ASD & 1 & $0.3 \%$ \\
Aortic valve repair & 1 & $0.3 \%$ \\
Ascending aorta repair & 2 & $0.5 \%$ \\
Carotid endarterectomy & 1 & $0.2 \%$ \\
Coronary artery bypass graft & 1 & $0.2 \%$ \\
\hline ASD Atial septal & &
\end{tabular}

$A S D$, Atrial septal defect; $T V P$, tricuspid valve annuloplasty. *Multiple procedures were performed in a single patient.

complications were calculated, as well as late follow-up, including survival and freedom from thromboembolism, endocarditis, valve failure, and reoperation. Statistical data
TABLE 4. Perioperative mortality and morbidity $(\mathbf{N}=358)$

\begin{tabular}{|c|c|c|}
\hline Operatie mortality & 0 & 0 \\
\hline \multicolumn{3}{|l|}{ Cardiac complications } \\
\hline New atrial fibrillation & $68 / 260$ & $26 \%$ \\
\hline Permanent pacemaker & 6 & $1.6 \%$ \\
\hline IABP required & 1 & $0.3 \%$ \\
\hline Myocardial infarction & 2 & $0.6 \%$ \\
\hline \multicolumn{3}{|l|}{ Other operative morbidity } \\
\hline $\begin{array}{l}\text { Pericardial effusion requiring } \\
\text { drainage }\end{array}$ & 6 & $1.6 \%$ \\
\hline Pleural effusion drained & 4 & $1.1 \%$ \\
\hline Reoperation for bleeding & 9 & $2.5 \%$ \\
\hline CVA documented by CT & 7 & $1.9 \%$ \\
\hline \multicolumn{3}{|l|}{ Wound complications } \\
\hline Dehiscence & 2 & $0.6 \%$ \\
\hline Superficial wound infection & 3 & $0.8 \%$ \\
\hline Deep sternal wound infection & 2 & $0.6 \%$ \\
\hline \multicolumn{3}{|l|}{ Vascular complications } \\
\hline Femoral vessel injury & 5 & $1.4 \%$ \\
\hline Pseudoaneurysm & 2 & $0.6 \%$ \\
\hline Ascending aortic dissection & 3 & $1.5 \%$ \\
\hline DVT/PE & 3 & $0.8 \%$ \\
\hline \multicolumn{3}{|l|}{ Hospital length of stay } \\
\hline Mean & $6.2 \pm 4.3$ & \\
\hline$\leq 5$ days & 208 & \\
\hline$\geq 7$ days & 97 & \\
\hline Transfer to rehabilitation center & 29 & $8 \%$ \\
\hline \multicolumn{3}{|l|}{ Homologous blood transfusion } \\
\hline None & 269 & $75 \%$ \\
\hline$\geq 1$ unit & 89 & $25 \%$ \\
\hline
\end{tabular}

$I A B P$, Intra-aortic balloon pump; $C V A$, cerebrovascular accident; $C T$, computed tomography; $D V T$, deep vein thrombosis; $P E$, pulmonary embolism.

are expressed as percent or mean $\pm 1 \mathrm{SD}$. Survival and time-related event analysis was performed by the KaplanMeier method. The statistical package used was Stata 6.0 for Windows (Stata Corporation, College Station, Tex). The operative results are shown in Table 4 . There were no operative deaths $(<30$ days or same hospital admission) in 358 patients. During the same period in the minimally invasive mitral valve replacement series, there was 1 death in the 51 procedures, that of a 91-year-old woman. Newonset atrial fibrillation occurred in 69 patients or $26 \%$ of those patients who were admitted in sinus rhythm. Placement of a permanent pacemaker for conjunctional rhythm or complete heart block occurred in 6 patients $(1.7 \%)$ and a myocardial infarction occurred in 2 patients $(0.5 \%)$. Anticoagulation with warfarin sodium (Coumadin) was given only to patients with atrial fibrillation postoperatively, either chronic or new onset. At 6 weeks, if the patient was in normal sinus rhythm, anticoagulation was discontinued. There were no major anticoagulation hematologic complications.

Peripheral vascular complications are listed in Table 4. There were 3 patients with deep venous thromboses $(0.82 \%)$, and 5 of 128 patients who had a femoral artery cannulation for bypass had a complication requiring an 
additional procedure $(3.9 \%)$. Three patients sustained a local ascending aortic dissection as a result of a cardioplegia needle placement diagnosed by transesophageal echocardiogram, requiring resection and grafting of the ascending aorta, all done through the same incision. Perioperative neurologic complications documented by computed tomographic scan showing a central defect occurred in 7 patients $(2 \%)$. Nine patients $(2.5 \%)$ were reoperated on for perioperative bleeding and 10 patients $(2.8 \%)$ had a pleural or pericardial effusion requiring postoperative drainage after hospital discharge. Wound complications were low, with a deep wound infection in 2 patients $(0.5 \%)$, superficial wound infections in 3 requiring antibiotics only, and a dehiscence of a right parasternal incision necessitating reoperation in 2 patients. The mean hospital stay was 6.2 days, with 208 patients having a stay of $\leq 4$ hospital days. Homologous red blood cells were transfused in 90 patients (25\%), although only $8 \%$ of the patients (28/358) were transferred to rehabilitation facilities after hospital discharge.

\section{Long-term Follow-up}

Duration of follow-up ranged from 0.6 to 69 months with a mean of $36 \pm 19$ months. Five patients $(1.4 \%)$ who live in foreign countries were lost to follow-up. The mean New York Heart Association functional class at follow-up was $1.2 \pm 0.5$ in $98 \%$ of the 353 patients available for evaluation. Late complications are summarized in Table 5. The survival curve shown in Figure 3 indicates a survival at 5 years of $95 \%$. The causes of late death in 12 patients were cardiac in 6 and other causes, such as cancer and accident, in the remaining 6 .

Reoperation for structural valve failure occurred in 21 of the 358 patients $(5.8 \%)$. The probability of freedom from reoperation is shown in Figure 4 and is $92 \%$ at 5 years. Twelve valve failures occurred in the first half of the series and 9 in the second half. On review of our results we found that valve repair failures fell into 4 categories. Six of 21 occurred due to failure of anterior leaflet repair. Anterior leaflet repair was done in 94 patients, so that $7 \%$ of those who had operations on the anterior leaflet either alone or because of bileaflet prolapse had a failed repair 1 to 18 months postoperatively. In a second group of 4 patients an annuloplasty ring was removed after the repair because of intractable systolic anterior motion of the mitral valve, usually due to placement of a small annuloplasty ring. Subsequently, these patients had a competent valve at the time of postbypass echocardiogram, but later, because of annular distortion, became incompetent once again. Since this experience, we tended to upsize the ring and continued to be very vigilant on the precise reduction of the height of the posterior leaflet. The mean ring size for myxomatous disease is $34 \mathrm{~mm}$. Two of the 4 were re-repaired 4 to 30
TABLE 5. Late follow-up data $(\mathbf{N}=\mathbf{3 5 8}$ )

\begin{tabular}{lcl}
\hline Mean follow-up & 36 mo & \\
Long-term follow-up & 5 & $1.4 \%$ \\
Late deaths & 12 & $3 \%$ \\
Failed repair & 21 & $5.8 \%$ \\
$\quad$ Anterior leaflet disease & 6 & \\
No ring & 4 & \\
New chordal rupture & 5 & \\
Advanced valve disease (Barlow, SBE) & 6 & \\
Thromboembolism & 3 & $1 \%$ \\
Endocarditis & 1 & $0.3 \%$
\end{tabular}

$S B E$, Subacute bacterial endocarditis.

months postoperatively by simply placing a larger ring. The third category of valve failure was new chordal rupture in 5 patients, 4 to 24 months postoperatively. One patient required rerepaired and the others required valve replacement. Finally, there was a mixed group of 6 patients in whom valve failure developed from 1 day to 42 months postoperatively because of very advanced valve disease. Two of these patients had endocarditis and the valve was quite distorted, while 4 patients had severe generalized Barlow syndrome involving all 6 areas of the valve. Three of these patients underwent rerepair, so that 7 of 21 valve failures were rerepaired at the second operation. There was no operative mortality at the mitral valve rerepair or replacement surgery.

\section{Discussion}

In 1996 several groups began to investigate the possibility of performing primary valve surgery through much smaller incisions than heretofore traditionally used, namely, the complete median sternotomy. Groups at Loma Linda, ${ }^{4}$, Paris, ${ }^{5}$ and Cleveland ${ }^{6}$, and somewhat later that year our group at Brigham, ${ }^{1}$ began to explore the use of parasternal and/or ministernotomy incisions for aortic and mitral valve replacement and repair. This stimulus came from the increasing use of minimally invasive surgical techniques for all branches of surgery, the last being cardiac surgery, which began with minimally invasive coronary bypass surgery in the 1990s. The small incisions, 6 to $8 \mathrm{~cm}$, were cosmetically appealing to patients, but the major question was could the same quality of operation be done through these small incision and could there be additional benefits, other than cosmetic, which could be helpful to patient care? Our initial paper on this subject, presented in 1997, ${ }^{1}$ investigated a concomitant group of 50 patients undergoing the same operation through a median sternotomy and compared them with our first 50 patients who had minimally invasive valve surgery, both aortic and mitral. We found that blood transfusion, hospital stay, and hospital costs were reduced, but most important, the patients recovered faster and returned to work more quickly. This study was 


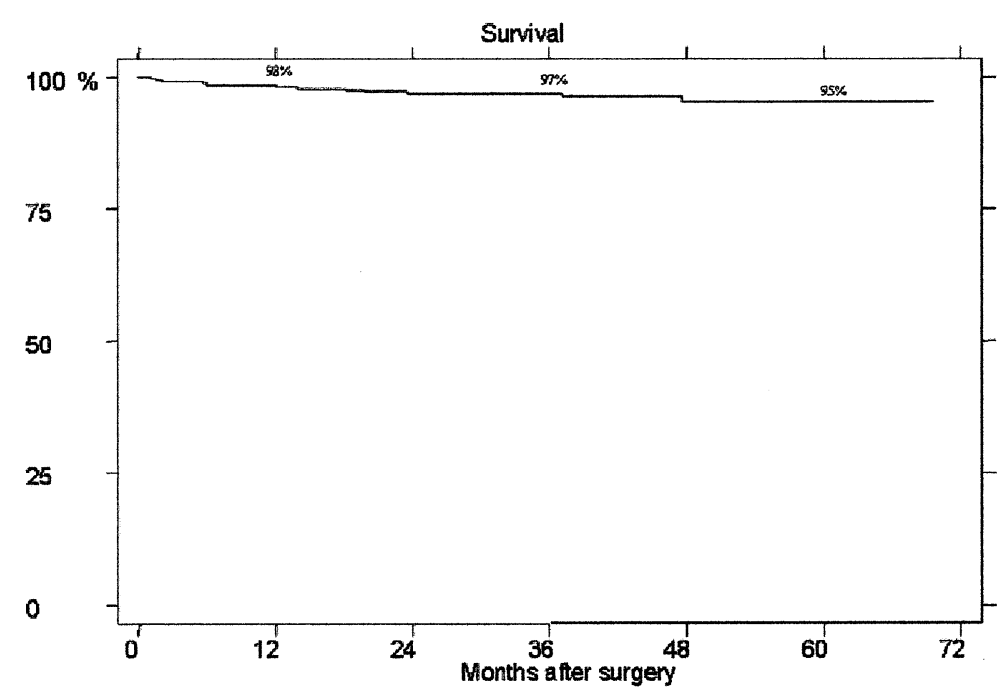

Figure 3. Kaplan-Meier curve of survival following minimally invasive mitral valve repair.

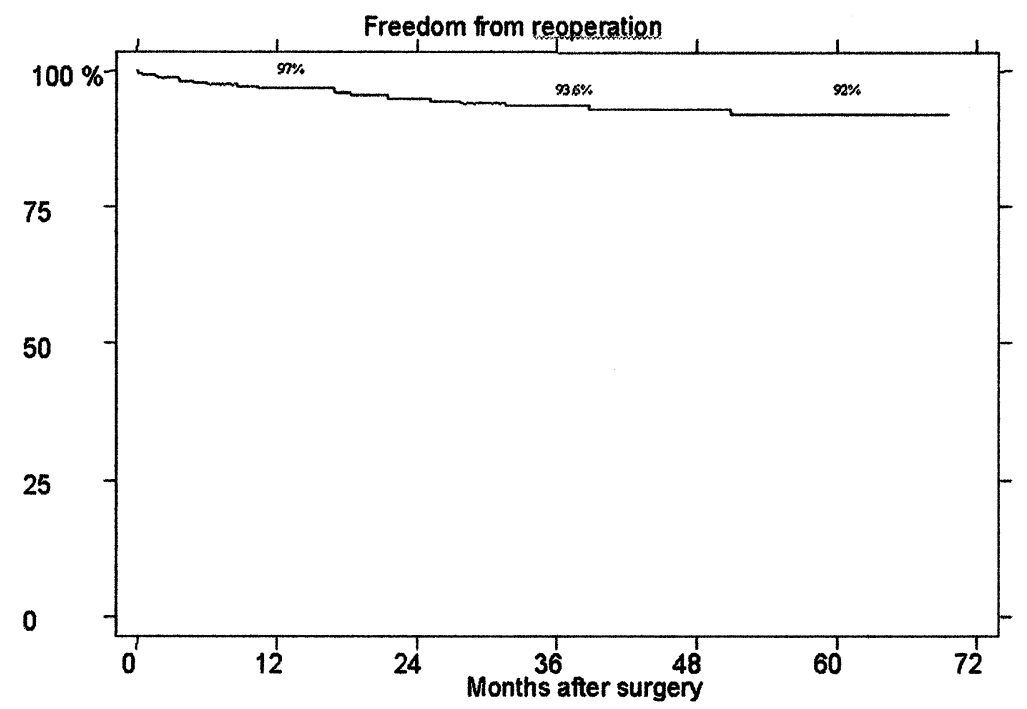

Figure 4. Kaplan-Meier curve of freedom from reoperation following minimally invasive mitral valve repair.

duplicated 1 year later with 100 patients in each group with the same conclusions. ${ }^{7}$

There have been relatively few reports on the medium- and long-term results after minimally invasive valve operations. ${ }^{8}$ The data presented here in a 6-year longitudinal study show that the operative risk is very low, and the vascular, neurologic, and cardiac complications are also low. Of particular interest is the low incidence of homologous blood transfusion (24\%), which has been duplicated in other series of minimally invasive valve operations. ${ }^{9,10} \mathrm{We}$ believe the latter is due to the small incision and the considerably smaller surface area exposed by these incisions. Crossclamp and bypass times have fallen as a result of increasing volume. The onset of these times were perhaps $30 \%$ to $50 \%$ greater than full sternotomy, but are now no different than open incision time. In addition, these operations have stimulated the miniaturization of the cardiopulmonary bypass circuit with vacuum-assisted venous drainage, ${ }^{2}$ which allows the use of very small cannula for venous drainage as well as smaller priming volumes for less hemodilution. As these patients do not have coronary artery disease, this is a low-risk population, but 79 patients (22\%) were $\geq 70$ years of age in this series, none of whom had an operative death.

The risk of failure of the valve repair, although not insignificant, is reasonable for the wide variety of valvular diseases, primarily advanced myxomatous degeneration including many patients with bileaflet prolapse and Barlow syndrome. Figure 2 shows the intraoperative transesopha- 
geal echocardiography score, before and after repair. The data again demonstrate the importance of placing an annuloplasty ring for every mitral valve repair ${ }^{11,12}$ as approximately one fourth of the patients who underwent a reoperation had no ring placed at the initial operation even though the valve was competent at that time. The incidence of repair failure was $7 \%$ in those with anterior leaflet disease and again documents the fact that anterior leaflet prolapse is more difficult to treat, which is documented in every series of mitral valve repairs. ${ }^{13,14}$ No patient was left with more than $2+\mathrm{MR}$, but many of these did fall into the reoperation group due to the causes outlined in Table 5 .

Over the 6-year period operative techniques have changed. Currently, we use a lower ministernotomy and the standard left atrial approach. No patient had to convert to a full sternotomy. Other minimally invasive approaches used and reported on recently with success are the port-access technique ${ }^{15}$ endscopically guided techniques, ${ }^{16}$ and the robotic assisted mitral valve repair surgery. ${ }^{17}$ All these studies similarly show low mortality and good medium-term results.

The present study documents the safety of minimally invasive mitral valve repair surgery in 358 patients. The low incidence of homologous blood utilization and the requirement for post-hospital rehabilitation confirms data from previous studies. We also document that the reparability of the mitral valve is quite high and the probability of valve failure after the learning curve is overcome is reasonably low. We believe this safe and efficacious operation will do much to lower the threshold for the early referral of patients undergoing mitral valve surgery.

\section{Limitations of the Study}

The major limitation of this study is that it is a retrospective study. Although all of the cardiac surgery data are collected from the Brigham Cardiac Surgical database to update the progress of patients, particularly for valve repair, patients had to be retrospectively contacted. We had a low rate of patients lost to follow-up (1.5\%). To truly gauge the effectiveness of the operation one would have to do a prospective randomized study, but we do not think this is feasible.

The second limitation is that we do not have consistent universal long-term echocardiographic data on every patient. We have data on approximately $75 \%$ of such patients and the results are quite good.

\section{References}

1. Cohn LH, Adams DH, Couper GS, et al. Minimally invasive cardiac valve surgery improves patient satisfaction while reducing costs of cardiac valve replacement and repair. Ann Surg. 1997;226:4 421-8.

2. Cosgrove DM, Sabik JF, Navia JL. Minimally invasive valve operations. Ann Thorac Surg. 1998;65:1535-8.

3. Doty D, DiRusso G, Doty J, et al. Full-spectrum cardiac surgery through a minimal incision: mini-sternotomy (lower half) technique. Ann Thorac Surg. 1998;65:56970.
4. Gundry SR, Shattuck OH, Razzouk AJ, et al. Facile minimally invasive cardiac surgery via ministernotomy. Ann Thorac Surg. 1998;65: 1100-4.

5. Carpentier A, Loulmet D, Carpentier A, et al. Chirurgie a coeur par video-chirurgie et mini-thoracotomie: premier cas (valvuloplastie mitrale) opere succes. Comptes Rendus De L'Academie des Sciences: Sciences de la Vie. 1996;319:219-23.

6. Navia JL, Cosgrove DM. Minimally invasive mitral valve operations. Ann Thorac Surg. 1996;62:1542-4.

7. Adams DH, Roborough DM, Couper GS, Cohn LH. Cardiac valve surgery through small access incisions is safe and associated with improved patient satisfaction. J Am Coll Cardiol.. 1998;31(suppl A): 68.

8. Mohr FW, Falk V, Diegler A, et al. Minimally invasive port-access mitral valve surgery. J Thorac Cardiovasc Surg. 1997;113:413-4.

9. Loulmet DF, Carpentier A, Cho PW, et al. Less invasive techniques for mitral valve surgery. J Thorac Cardiovasc Surg. 1998;115:567-74.

10. Chitwood WR Jr, Elbeery JR, Chapman WH, et al. Video-assisted minimally invasive mitral valve surgery: the "micro-mitral" operation. J Thorac Cardiovasc Surg. 1997;113:413-4.

11. Carpentier A. Cardiac valve surgery: the "French correction." J Thorac Cardiovasc Surg. 1983;86:323-47.

12. Cohn LH, Couper GS, Aranki SF, Rizzo RJ, Kinchla NM, Collins JJ Jr. Long-term results of mitral valve reconstruction for regurgitation of the myxomatous mitral valve. J Thorac Cadiovasc Surg. 1994;107: 143-51.

13. Braunberger E, Deloche A, Berrebi A, et al. Very long-term results (more than 20 years) of valve repair with Carpentier's techniques in non-rheumatic mitral valve insufficiency. Circulation. 2001; 104(Suppl):I8-11.

14. Mohty D, Orszulak TA, Schaff HV, Avierinos JF, Tajik JA, EnriquezSarano M. Very long-term survival and durability of mitral valve repair for mitral valve prolapse. Circulation. 2001;104(Suppl):I1-7.

15. Grossi EA, Galloway AC, Rebakove GH, et al. Impact of minimally invasive valvular heart surgery: a case control study. Ann Thorac Surg. 2001;71:807-10.

16. Casselman FP, Van Slycke S, Dom H, Lambrechts DL, Vermeulen Y, Vanermen H. Totally endoscopic mitral valve repair: feasible, reproducible, and durable. J Thorac Cardiovasc Surg. 2002;125:273-82.

17. Felger JE, Nifong LW, Chitwood WR Jr. The evolution of and early experience with robot-assisted mitral valve surgery. Surg Laparosc Endosc Percutan Tech. 2002;12:58-63.

\section{Discussion}

Dr Scot Merrick (San Francisco, Calif). Anybody who does mitral valve surgery is well aware of the exceptional contributions of your group, particularly Dr Cohn, over the past several decades in the advancement of mitral valve surgery, and I think this paper is a clear reflection of what you have accomplished.

Mitral valve surgery through small incisions is clearly here to stay. However, can you do the same techniques through a small incision that you can through regular incision? Are they safe? Will you get the same long-term results? I think you have gone a long way to answer some of these questions.

I do have a couple of questions for you. One relates to patient selection. Most of your patients were relatively young, had very little comorbidity, had myxomatous disease and mostly of the posterior leaflet. How did you determine what type of incision to make in this group of patients? I notice that you did do 51 procedures through a standard incision. Were there criteria that you used to select out these patients for a large incision, which would make you avoid doing a small incision?

Dr Greelish. That is an insightful question. This patient population does represent a younger population with less comorbidity, but that in general reflects our philosophy at the Brigham. My 